\section{$\underset{\substack{\text { hommes } \\ \text { \& migrations }}}{ }$}

\section{Hommes \& migrations}

Revue française de référence sur les dynamiques

migratoires

$1330 \mid 2020$

1973, l'année intense

\title{
Akila Kizzi, Marie-Louise Taos Amrouche. Passions et déchirements identitaires
}

Fauves éditions, Paris, 2019, 488 pages, $25 €$.

\section{Mustapha Harzoune}

\section{(2) OpenEdition}

Journals

Édition électronique

URL : https://journals.openedition.org/hommesmigrations/11666

DOI : 10.4000/hommesmigrations. 11666

ISSN : 2262-3353

Éditeur

Musée national de l'histoire de l'immigration

Édition imprimée

Date de publication : 17 juillet 2020

Pagination : 239

ISBN : 978-2-919040-51-3

ISSN : 1142-852X

Référence électronique

Mustapha Harzoune, "Akila Kizzi, Marie-Louise Taos Amrouche. Passions et déchirements identitaires », Hommes \& migrations [En ligne], 1330 | 2020, mis en ligne le 01 juillet 2020, consulté le 04 janvier 2023. URL : http://journals.openedition.org/hommesmigrations/11666 ; DOI : https://doi.org/10.4000/ hommesmigrations. 11666 
Livres

Marie-Louise Taos

Amrouche. Passions et déchirements identitaires

Akila Kizzi, Paris, Fauves

éditions, 2019, 488 pages, $25 €$

Docteure en littérature francophone et études de genre, spécialiste des écritures féminines du Maghreb et des diasporas, l'auteure enseigne à l'université Paris-8 Saint-Denis. Avec ce pavé, dense et ailé, où l'émotion se dispute à la rigueur scientifique, Akila Kizzi offre à Taos Amrouche l'occasion de se rappeler aux bons souvenirs des oublieux et d'ouvrir, aux plus jeunes, quelques horizons - car la vie et l'œuvre de cette femme de feu et de conviction née en 1913, dont le premier roman fut écrit en 1939 et publié en 1947, restent un enseignement. Il faut le 


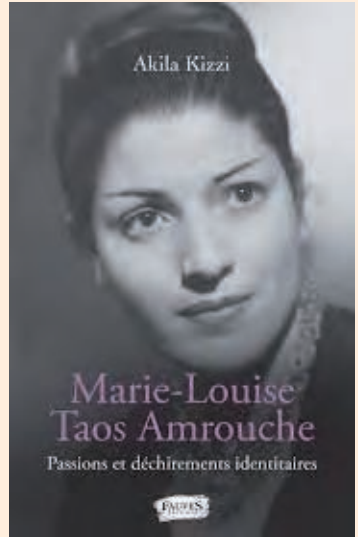

répéter: dans un monde - pas seulement en Kabylie - où le primat revient toujours aux hommes; dans une famille où plane l'ombre d'un frère illustre; dans un pays hostile à ses langue et culture millénaires; dans une «tribu » où par sa foi elle était une minoritaire voire une «m'tourni»; dans un espace d'expression et de création, celui de la littérature, de tradition masculine; dans un temps de guerre, pour l'indépendance, être et se dire française; sur une terre d'exil, fardée d'humanisme et d'universalisme, être renvoyée à son étrangeté... tout, absolument tout, se dressait comme autant d'obstacles insurmontables sur la trajectoire existentielle et créatrice de Taos Amrouche. Femme, sœur «de», kabyle, chrétienne, exilée, algérienne, française... voilà de quoi était fait le tissu identitaire de cette femme d'exception, ce qu'elle appelait ces «fidélités antagonistes».

Cette étude où le littéraire croise la biographie rappelle que Taos Amrouche fut la première des romancières algériennes, avant Djamila Debbèche ou Assia Djebar, avant Mouloud Feraoun ou Mouloud Mammeri. Elle fut en avance et aux avant-postes. En éclaireuse exigeante et perspicace, elle a ouvert la voie, donner des repères pour gravir les difficiles chemins de l'«hybridité» sur lesquels grimpent et s'essoufflent parfois, parce que sans boussole et sans fondement, ses enfants et petits-enfants nés des modernes rencontres et migrations. Depuis son premier roman jusqu'à Solitude ma mère, elle n'a cessé d'interroger «la différence, la liberté, l'exil, l'écriture, le chant, l'amour, l'identité, l'engagement, et le combat». L'altérité aussi, la sienne, femme, kabyle, chrétienne, française, auteure, exilée, luttant corps et âme contre les dominations de genre, de classe, de culture, du centre sur la marge. Elle le fit en refusant les identités monolithiques, soucieuse d'universaliser le legs reçu des ancêtres et du dialogue avec l'Autre. Elle osa, solitaire et armée de sa seule voix, dernier maillon d'une chaine de transmission de mère à fille, porter une langue antique et fière, ses chants, l'âme de sa tribu; affrontant l'hostilité, le mépris des dirigeants de son pays et les soupçons qui pèse, en France, sur les être de l'ailleurs pour paraphraser René Char.

Akila Kizzi éclaire l'écriture inventive de Taos Amrouche, «l'autobiographie comme genre à part entière», son "écriture de nécessité», "contestataire et libératrice». Elle replace l'œuvre et la vie de Taos Amrouche dans leur contexte socio-historique et littéraire, appuyant sur les enjeux, les rapports de domination et le poids des discriminations. Akila Kizzi esquisse ici un contre discours à partir des voix (et des écrits) de femmes, une contre histoire aussi, qui restitue la pluralité des héritages et des identités, une autre histoire monde, avant l'heure!

Taos Amrouche s'est éteinte le 2 avril 1976. Elle, qui se produisit sur les scènes de Fez à Florence, de Dakar à Paris, n'a jamais chanté, officiellement, en Algérie. En 1969, dans le grand barnum idéologique du Festival panafricain, les autorités algériennes lui refusèrent le droit de porter, sur sa terre, ces chants berbères venus du fond des âges. Inflexible, invitée par des membres du Cercle culturel berbère, elle chantera pour les étudiants de la cité universitaire de Ben Aknoun. M. H. 